\title{
Patient waiting time in hospital emergency departments of Iran: A systematic review and meta-analysis
}

\author{
Seyed Mohammad Esmaeil Fazl Hashemi ${ }^{1}$, Ali Sarabi Asiabar ${ }^{1}$, Aziz Rezapour $^{1}$, \\ Saber Azami-Aghdash², Hassan Hosseini Amnab ${ }^{1}$, Seyed Abbas Mirabedini ${ }^{1 *}$
}

\section{Abstract}

Background: Waiting time in emergency department is a key indicator in measuring the quality of hospital services and has a significant impact on patient satisfaction The purpose of this study was to conduct a systematic review and meta-analysis of the patients' waiting time in hospital emergency departments in Iran.

Methods: Data were collected from databases of Web of Science, Embase, PubMed, Scopus, Google scholar, SID, and Iran Medex using the following key words: "emergency ward", "emergency room", "waiting time", " time delay", "first visit", "first treatment", "emergency department", "Iran", and their Persian equivalents. The timeframe of 2000 to 2016 was selected to search the articles. CMA 2 (Comprehensive Meta-Analysis) software was used in this meta-analysis.

Results: A total of 236 articles were extracted from databases and other sources, and finally 17 articles were included in the analysis. In total, waiting time in different parts of the emergency department was measured for 15943 patients. Mean \pm SD waiting time was 5.9 \pm 0.6 minutes from the arrival to the first visit by a physician, it was $45 \pm 5$ minutes between the first visit and the first therapeutic steps, $94 \pm 33.9$ minutes between referring to the laboratory and receiving the result, $23.2 \pm 3$ minutes between referring to the radiology and receiving the result, and $32.2 \pm 7$ minutes between referring to ECG and receiving the result; moreover, waiting time for the first specialist consultation was $99.3 \pm 32.8$ minutes.

Conclusion: The results demonstrated that waiting time in the emergency rooms of Iranian hospitals was higher than the national and international standards. According to the high rate of heterogeneity in the results and probability of publication bias, we highly recommend that readers use the results of this study and pay sufficient attention to this issue.

Keywords: Emergency, Waiting time, Timing, Quality

Copyright@ Iran University of Medical Sciences

Cite this article as: Fazl Hashemi SME, Sarabi Asiabar A, Rezapour A, Azami-Aghdash S, Hosseini Amnab H, Mirabedini SA. Patient waiting time in hospital emergency departments of Iran: A systematic review and meta-analysis. Med J Islam Repub Iran. 2017 (14 Dec);31:79. https://doi.org/10.14196/mjiri.31.79

\section{Introduction}

An important part of any hospital is the emergency department $(1,2)$. In other words, emergency department is known as the heart of the hospital $(3,4)$. This department has a sensitive and exceptional position because of its fast,

Corresponding author: Seyed Abbas Mirabedini, mirabedini110@yahoo.com

1. Health Management and Economics Research Center, Iran University of Medical Sciences, Tehran, Iran.

2. Tabriz Health Services Management Research Center, Tabriz University of Medical Sciences, Tabriz, Iran high quality, and effective services and because of providing multiple and complex care in the hospital and health care system $(5,6)$.

Long waiting time in the emergency room may reduce services to other patients requiring emergency medical

$\uparrow$ What is "already known" in this topic:

High waiting time is an important factor in negative attitudes toward hospital and health service providers.

\section{$\rightarrow$ What this article adds:}

In Iran, waiting time in different parts of the emergency department was not satisfactory. Average waiting times from arrival to the first visit by a physician was $8.1 \pm 0.6$, from the first visit and the first therapeutic steps $5.3 \pm 49.6$, from referring to the laboratory and getting the result $33.9 \pm 94$, from referring to the radiology and getting the result $2.9 \pm 34.4$, and for the first specialist consultation was $32.8 \pm 99.3$ minutes. 


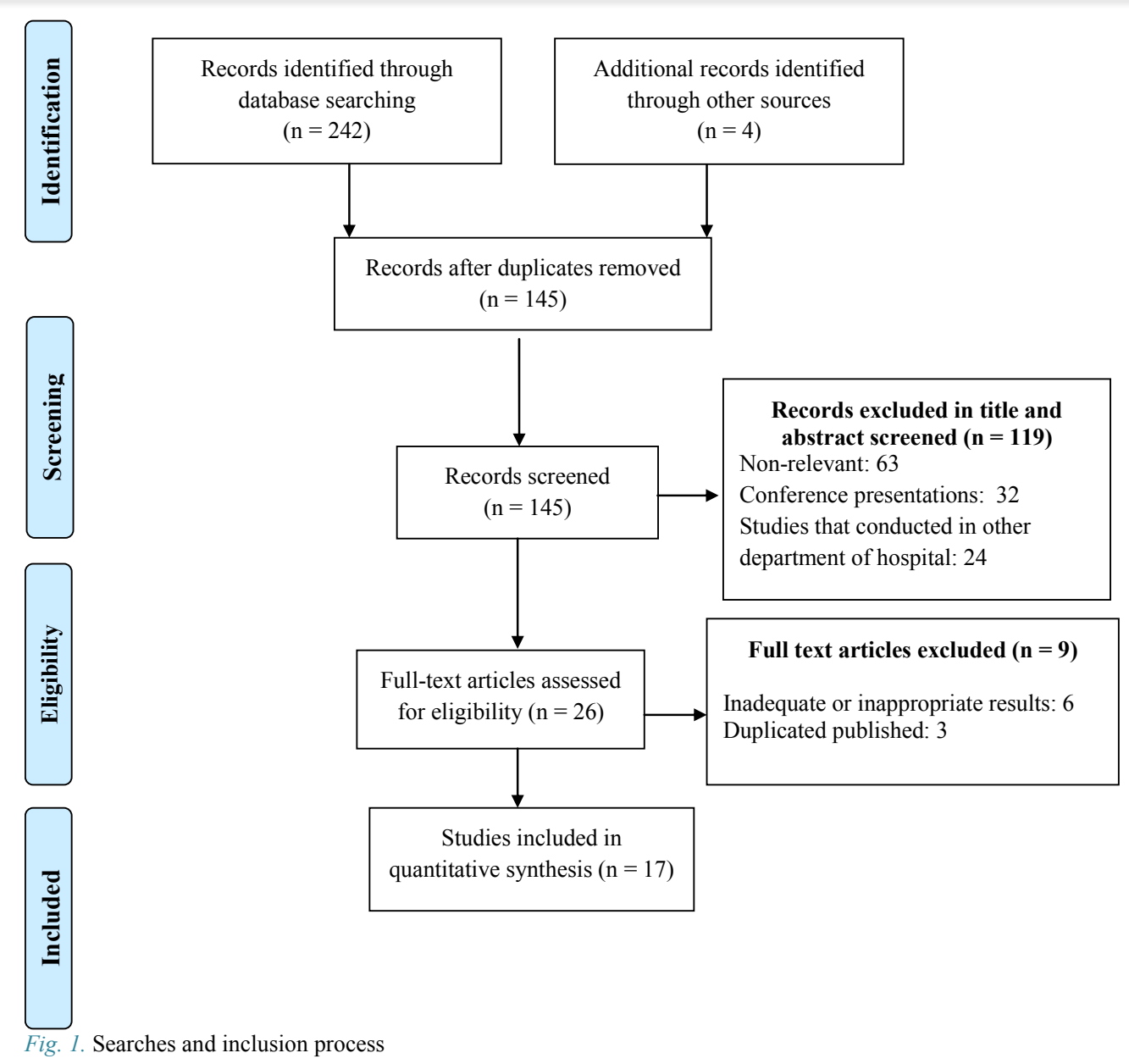

care, and this will cause dissatisfaction of the patients and increased risks and side effects of the diseases and events (7-11). Due to inherent complexities of health systems, a change in one area of the health system can lead to changes in other areas. For this reason, all sectors, including the emergency department, should be considered in determining the policies in the hospital (12).

Compiling quantitative and qualitative standards and identifying a range of authentic and scientific indicators, such as timing and expected reduction, in patients' waiting time in emergency services are the most important activities in any emergency department (13-15). Waiting time represents the amount of accessing the emergency department services and hospital services, and it is also one of the key performance indicators, which is measurable in a hospital (15-18). The high waiting time for emergency department services is a serious problem in hospitals, which may reduce patient satisfaction and quality of service (19). It is essential for healthcare organizations to have ready and effective leaders who reduce waiting time (20). Moreover, high waiting time is an important factor in negative attitudes towards the hospital and health service providers, and it is considered a major challenge to public's trust in the health system (21-23).

According to the studies in the emergency departments of hospitals in Iran, it seems that waiting time in different parts of the emergency department is not satisfactory. In this regard, a study was conducted by Golaghaei et al. in emergency medical rooms of teaching hospitals in Arak, Iran and found a long waiting time for the patients (24). Various other studies have been performed on hospital emergency waiting time of patients in Iran. However, these studies, due to their small sample size and investigating a limited geographical area, could not be considered as sufficient evidence to make a clear picture for the planners and policy makers. Thus, it seemed necessary to pool the results of different studies to provide a clear and comprehensive description about the state of patients' waiting time in the emergency departments of hospitals in Iran, which could help the planners and policy makers a great deal. The purpose of this study was to conduct a systematic review and meta-analysis of the patients' waiting time in hospital emergency departments in Iran.

\section{Methods}

This was a systematic review of studies according to evidence-based medicine and systematic review services that were performed in 2016.

\section{Searching strategy}

The required information was gathered from Web of science, Embase, PubMed, Scopus, Google scholar, Sid, and Iran Medex databases using the following key words: "emergency ward", "emergency room", "waiting time"," 


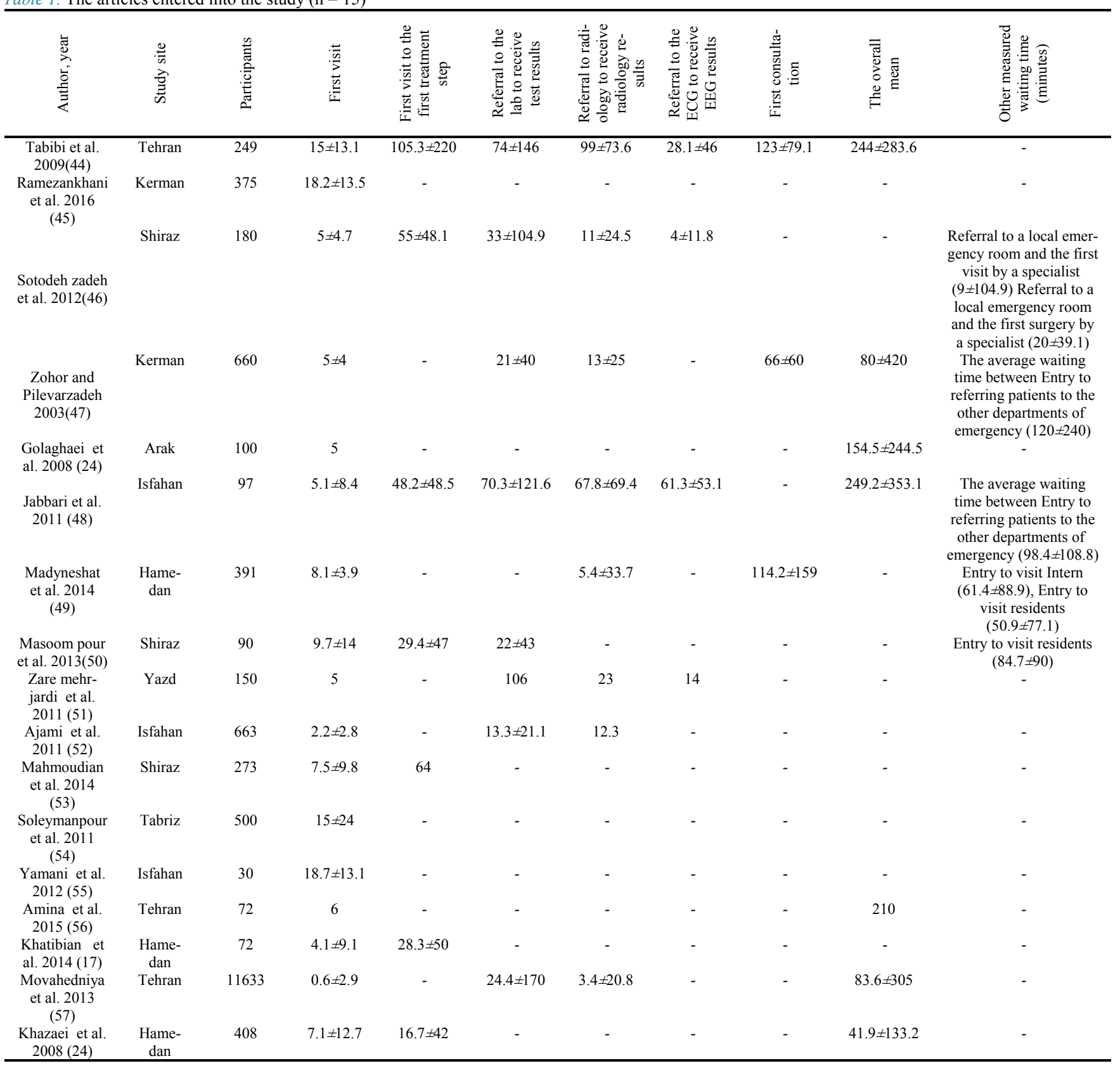

time delay", "first visit", "first treatment", "emergency department", "Iran", and their Persian equivalents. The timeframe of 2000 to 2016 was selected to search the articles. Also, many prestigious journals in the field were searched manually for more coverage. After excluding those studies that had a poor connection with the study objectives, we selected the main studies and searched their references again on the internet to enhance the reliability of the identification and review of the existing articles.

\section{Inclusion and exclusion criteria}

The inclusion criteria were as follow: referring to the waiting time of at least one step of the hospital emergency department services; and studies conducted during January
1, 2000 and December 31, 2016 in Iran. Exclusion criteria were as follow: articles published in languages other than English and Farsi; papers presented at conferences that had no full-text available; and articles that assessed waiting times in other parts of the hospital.

\section{Assessing the quality of articles}

After extraction of articles from the databases using the mentioned key words, their quality was evaluated by 2 assessors independently. The assessment tool was the checklist of strengthening the reporting of observational studies in epidemiology (STROBE). This checklist was selected because of its specificity to evaluate observational studies. 


\begin{tabular}{|c|c|c|c|c|c|c|c|c|}
\hline \multirow[t]{2}{*}{ Study name } & \multirow[b]{2}{*}{ Mean } & \multirow[b]{2}{*}{$\begin{array}{l}\text { Standard } \\
\text { error }\end{array}$} & \multicolumn{3}{|c|}{ Statistics for each study } & \multirow[b]{2}{*}{ Z-Value } & \multirow[b]{2}{*}{ p-Value } & \multirow[t]{2}{*}{ Mean and $95 \% \mathrm{Cl}$} \\
\hline & & & Variance & $\begin{array}{c}\text { Lower } \\
\text { limit }\end{array}$ & $\begin{array}{c}\text { Upper } \\
\text { limit }\end{array}$ & & & \\
\hline Setoodehzadeh F, et al:2014 & 5.000 & 0.350 & 0.123 & 4.313 & 5.687 & 14.273 & 0.000 & \\
\hline Zohoor A and Pilevar Zadeh M, 2003 & 5.000 & 0.156 & 0.024 & 4.695 & 5.305 & 32.113 & 0.000 & \\
\hline Golaghaie $F$, et al:2008 & 5.000 & 0.400 & 0.160 & 4.216 & 5.784 & 12.500 & 0.000 & \\
\hline Jabbari A, et al:2011 & 5.100 & 0.853 & 0.727 & 3.428 & 6.772 & 5.980 & 0.000 & \\
\hline MaddiNeshat M, et al:2015 & 8.100 & 0.197 & 0.039 & 7.713 & 8.487 & 41.068 & 0.000 & \\
\hline Masoumpour S, et al:2013 & 9.700 & 1.476 & 2.178 & 6.808 & 12.592 & 6.573 & 0.000 & \\
\hline Zare Mehrjardi Y, et al:2011 & 5.000 & 0.286 & 0.082 & 4.440 & 5.560 & 17.496 & 0.000 & \\
\hline Ajami S, et al:2013 & 2.200 & 0.109 & 0.012 & 1.987 & 2.413 & 20.231 & 0.000 & \\
\hline Mahmoodian F, et al:2014 & 7.500 & 0.593 & 0.352 & 6.338 & 8.662 & 12.645 & 0.000 & \\
\hline Amina S, et al:2015 & 6.000 & 0.471 & 0.222 & 5.076 & 6.924 & 12.728 & 0.000 & \\
\hline Khatiban M, et al:2014 & 4.100 & 1.072 & 1.150 & 1.998 & 6.202 & 3.823 & 0.000 & \\
\hline Movahednia S, et al:2013 & 2.900 & 0.006 & 0.000 & 2.889 & 2.911 & 521.306 & 0.000 & \\
\hline \multirow[t]{2}{*}{ Khazaei A, et al:2015 } & 12.700 & 0.352 & 0.124 & 12.011 & 13.389 & 36.131 & 0.000 & \\
\hline & 5.955 & 0.637 & 0.406 & 4.706 & 7.204 & 9.345 & 0.000 & \\
\hline
\end{tabular}

Fig. 2. Frequency distribution of the average waiting time for the first visit of emergency patients in Iran

\begin{tabular}{|c|c|c|c|c|c|c|c|}
\hline \multirow[t]{2}{*}{$\underline{\text { Study name }}$} & \multicolumn{7}{|c|}{ Statistics for each study } \\
\hline & Mean & $\begin{array}{l}\text { Standard } \\
\text { error }\end{array}$ & Variance & $\begin{array}{c}\text { Lower } \\
\text { limit }\end{array}$ & $\begin{array}{l}\text { Upper } \\
\text { limit }\end{array}$ & Z-Value & p-Value \\
\hline Setoodehzadeh $F$, et al: & 2554000 & 3.585 & 12.853 & 47.973 & 62.027 & 15.341 & 0.000 \\
\hline Jabbari $A$, et al:2011 & 48.200 & 4.924 & 24.250 & 38.548 & 57.852 & 9.788 & 0.000 \\
\hline Masoumpour $\mathrm{S}$, et al:20 & 139.400 & 4.954 & 24.544 & 19.690 & 39.110 & 5.934 & 0.000 \\
\hline Mahmoodian F, et al:201 & 464.000 & 2.905 & 8.440 & 58.306 & 69.694 & 22.030 & 0.000 \\
\hline Khatiban M, et al:2014 & 28.300 & 5.893 & 34.722 & 16.751 & 39.849 & 4.803 & 0.000 \\
\hline Khazaei A, et al:2015 & 42.000 & 0.827 & 0.684 & 40.380 & 43.620 & 50.800 & 0.000 \\
\hline & 45.047 & 5.032 & 25.325 & 35.184 & 54.911 & 8.951 & 0.000 \\
\hline
\end{tabular}

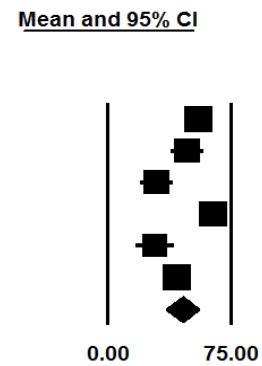

Fig. 3. Frequency distribution of the average waiting time of first visit to the first treatment step in emergency departments in Iran

The Persian translation of the checklist had been prepared and validated previously (26); the checklist has 22 items $(27,28)$. In this study, those articles, whose at least half of their items were not observed (11 out of 22 cases), were excluded.

\section{Data extraction}

Data extraction form was designed in Microsoft Word software. Initially, 3 trial articles were extracted; then, the data extraction form was revised to cover all required data. Extracted data included the following information: author; year; study site; participants; waiting time for first visit; time lag between the first visit to the first treatment step; time between referring to the lab and receiving the test results; referring to radiology department to receive radiology results; referring to the ECG to receive EEG results; time lag for the first specialist consultation; the overall mean waiting time; and other measured waiting time (minutes).

\section{Data analysis methods}

The statistical techniques of meta-analysis with random effect model were used to calculate the average values of the emergency waiting times in different parts of the emergency department. CMA 2 software (Comprehensive MetaAnalysis Englewood, NJ 07631 USA) was used for metaanalysis. Forest plot diagrams were used to report the results. The results of heterogeneity measurements were presented by $\mathrm{Q}$ and $\mathrm{I}^{2}$ index. In this study, $\mathrm{I}^{2}$, which was above $50 \%$, was a good criterion for heterogeneity of the articles.

\section{Results}

Out of 236 studies, 91 were excluded in database search and other sources due to duplication, 119 were excluded in the title and abstract assessment, and 9 were excluded in full text assessment. Finally, 17 articles were included in the synthesis (Fig. 1).

Articles that entered into the analysis are summarized in Table 1.

Waiting time in different parts of emergency department was evaluated for 15943 patients.

The results of the meta-analysis with random model revealed that the mean \pm SD waiting time for the first visit of emergency patients in Iran was $5.9 \pm 0.6$ minutes $(95 \% \mathrm{CI}$ : 4.7,7.2) (heterogeneity test $[\mathrm{Q}=1942.4, \mathrm{df}=12, \mathrm{p}<0.001$, $\left.\left.\mathrm{I}^{2}=91.2\right]\right)$. In this section, the results of Tabibi et al. (2009), Ramezankhani et al. (2016), Soleymanpour et al. (2011), and Yamani et al. (2012) studies were not included in the meta-analysis due to high heterogeneity (Fig. 2).

The mean \pm SD waiting time in the emergency departments of Iran between first visit and the first treatment step was $45 \pm 5$ minutes $(95 \% \mathrm{CI}: 35.1,54.9)$ (heterogeneity [Q= $\left.\left.48.9, \mathrm{df}=5, \mathrm{p}<0.001, \mathrm{I}^{2}=87.8\right]\right)$. In this section, the results of Tabibi et al. (2009) study were not included in the metaanalysis due to high heterogeneity (Fig. 3).

The mean \pm SD waiting time between referring to the lab and receiving test results was $94 \pm 33.9$ minutes $(95 \% \mathrm{CI}$ : $27.4,160.6$ ) (heterogeneity test $[\mathrm{Q}=2429.9, \mathrm{df}=7$, $\left.\mathrm{p}<0.001, \mathrm{I}^{2}=99.7\right]$ ) (Fig. 4).

The mean \pm SD waiting time between referring to the radiology department and receiving radiology results was $23.2 \pm 3$ minutes $(95 \%$ CI: $17.2,29.1)$ (heterogeneity test $\mathrm{Q}=$ 
Study name

\begin{tabular}{lr}
\hline & Mean \\
Tabibi SJ, et al:2009 & 146.000 \\
Setoodehzadeh F, et al:2014 & 104.900 \\
Zohoor A and Pilevar Zadeh M, 2003 & 40.000 \\
Jabbari A, et al:2011 & 121.600 \\
Masoumpour S, et al:2013 & 43.000 \\
Zare Mehrjardi Y, et al:2011 & 106.000 \\
Ajami S, et al:2013 & 21.100 \\
Movahednia S, et al:2013 & 170.000 \\
& 94.041
\end{tabular}

\begin{tabular}{|c|c|c|c|c|c|}
\hline \multirow[b]{2}{*}{$\begin{array}{l}\text { Standard } \\
\text { error }\end{array}$} & \multicolumn{3}{|c|}{ Statistics for each study } & \multirow[b]{2}{*}{ Z-Value } & \multirow[b]{2}{*}{ p-Value } \\
\hline & Variance & $\begin{array}{c}\text { Lower } \\
\text { limit }\end{array}$ & $\begin{array}{l}\text { Upper } \\
\text { limit }\end{array}$ & & \\
\hline 4.690 & 21.992 & 136.809 & 155.191 & 31.133 & 0.000 \\
\hline 2.460 & 6.050 & 100.079 & 109.721 & 42.648 & 0.000 \\
\hline 0.817 & 0.668 & 38.398 & 41.602 & 48.934 & 0.000 \\
\hline 7.138 & 50.949 & 107.610 & 135.590 & 17.036 & 0.000 \\
\hline 2.319 & 5.378 & 38.455 & 47.545 & 18.542 & 0.000 \\
\hline 4.654 & 21.660 & 96.878 & 115.122 & 22.776 & 0.000 \\
\hline 0.517 & 0.267 & 20.088 & 22.112 & 40.850 & 0.000 \\
\hline 0.226 & 0.051 & 169.557 & 170.443 & 751.458 & 0.000 \\
\hline 33.998 & 1155.838 & 27.407 & 160.675 & 2.766 & 0.00 \\
\hline
\end{tabular}

Mean and $95 \% \mathrm{Cl}$

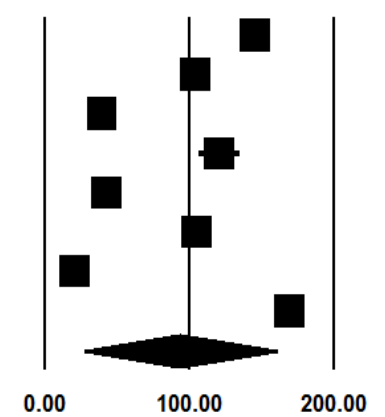

Fig. 4. Frequency distribution of the average waiting time between referring to the lab and receiving test results in emergency departments in Iran

Study name

$\begin{array}{lccccccc} & \text { Mean } & \begin{array}{c}\text { Standard } \\ \text { error }\end{array} & \text { Variance } & \begin{array}{c}\text { Lower } \\ \text { limit }\end{array} & \begin{array}{c}\text { Upper } \\ \text { limit }\end{array} & \begin{array}{l}\text { Z-Value } \\ \text { p-Value }\end{array} \\ \text { Setoodehzadeh F, et al:2014 } & 24.500 & 0.820 & 0.672 & 22.893 & 26.107 & 29.882 & 0.000 \\ \text { Zohoor A and Pilevar Zadeh M, 2003 } & 25.000 & 0.506 & 0.256 & 24.008 & 25.992 & 49.405 & 0.000 \\ \text { MaddiNeshat M, et al:2015 } & 33.700 & 0.273 & 0.075 & 33.165 & 34.235 & 123.403 & 0.000 \\ \text { Zare Mehrjardi Y, et al:2011 } & 23.000 & 0.980 & 0.960 & 21.080 & 24.920 & 23.474 & 0.000 \\ \text { Ajami S, et al:2013 } & 12.300 & 0.466 & 0.217 & 11.387 & 13.213 & 26.393 & 0.000 \\ \text { Movahednia S, et al:2013 } & 20.800 & 0.032 & 0.001 & 20.738 & 20.862 & 659.827 & 0.000 \\ & 23.218 & 3.028 & 9.170 & 17.283 & 29.153 & 7.667 & 0.000\end{array}$

Mean and $95 \% \mathrm{Cl}$

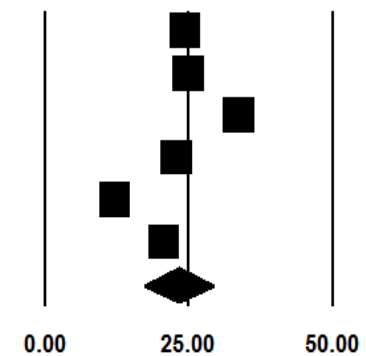

Fig. 5. Frequency distribution of the average waiting time between referring to radiology and receiving radiology results in the emergency departments in Iran

$\left.\left.678.6, \mathrm{df}=5, \mathrm{p}<0.001, \mathrm{I}^{2}=91.4\right]\right)$. In this section, the results of Tabibi et al. (2009) and Jabbari et al. (2011) studies were not included in the meta-analysis due to high heterogeneity (Fig. 5).

The mean \pm SD waiting time in Iran's emergency departments between referral and receiving the ECG result was $32.2 \pm 7$ minutes $(95 \% \mathrm{CI}: 18.4,46.1)$ (heterogeneity test $\left[\mathrm{Q}=440.7, \mathrm{df}=3, \mathrm{p}<0.001, \mathrm{I}^{2}=99.3\right]$ ) (Fig. 6).

The mean \pm SD waiting time in Iran's emergency departments for the first specialist consultation was $99.3 \pm 32.8$ minutes (95\% CI: 34.9, 163.6) (heterogeneity test $[\mathrm{Q}=$ 245.4, $\left.\mathrm{df}=2, \mathrm{p}=0.00, \mathrm{I}^{2}=99.1\right]$ ) (Fig. 7).

The results of the meta-analysis with random effect model revealed that the mean \pm SD total waiting time (entry to exit) in the emergency departments of Iran was $276.7 \pm 45.2$ minutes $(95 \%$ CI: $188.1,365.4)$ (heterogeneity test $\left.\left[\mathrm{Q}=49.7, \mathrm{df}=6, \mathrm{p}=0.00, \mathrm{I}^{2}=91.9\right]\right)$ (Fig. 8).

Publication bias was evaluated by funnel plot (Fig. 9). Funnel plot results revealed the high probability of publication bias among studies results.

\section{Discussion}

Results of this study revealed that the mean waiting time from arriving at an emergency department in Iranian hospital was as follows: the first visit by a doctor took $5.9 \pm 0.6$ minutes from entrance; first visit to the first therapeutic steps took $45 \pm 5$ minutes; waiting time for referring to the lab till receiving the test results was $94 \pm 33.9$ minutes; referring to radiology till receiving radiology results took $34.4 \pm 2.9$ minutes; referring to ECG till receiving ECG results took $32.2 \pm 7$ minutes, and finally, it took $99.3 \pm 32.8$ minutes from consultation request to the first consultation by a specialist. The average total waiting time (entry and exit) in the emergency departments was $276.7 \pm 45.2$ minutes.

The results revealed that waiting time between referring to the lab and receiving the test results was 94 minutes. Findings of Lee et al. (2015), who examined the waiting time response and emergency labs for 27656 patients in several hospitals in Australia, revealed that the average waiting time to receive the test results was about 66 minutes (29). In 1999, Howanitz et al. in an American study, which is known as Q-Probes and is a standard reference in providing potassium and hemoglobin test results in emergency department, recommended 45 minutes to present the results of tests in the emergency department (30). Also, different studies have shown that reducing the time in receiving the results of lab tests in the emergency department has a significant impact on reducing the overall waiting time for the patients (31-34). Perhaps, one of the reasons for the delayed response and preparing test results was the lack of a separate laboratory within the emergency department of some 


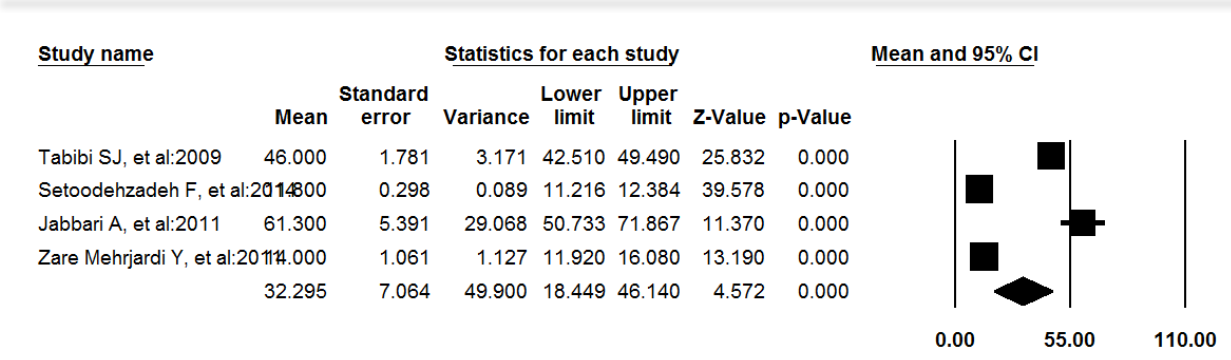

Fig. 6. Frequency distribution of the average waiting time between referring to the ECG and receiving EEG results in emergency departments in Iran

\begin{tabular}{|c|c|c|c|c|c|c|c|}
\hline \multirow[t]{2}{*}{ Study name } & \multirow[b]{2}{*}{ Mean } & \multicolumn{4}{|c|}{ Statistics for each study } & \multirow[b]{2}{*}{ Z-Value } & \multirow[b]{2}{*}{$\mathrm{p}$-Value } \\
\hline & & $\begin{array}{l}\text { Standard } \\
\text { error }\end{array}$ & Variance & $\begin{array}{l}\text { Lower } \\
\text { limit }\end{array}$ & $\begin{array}{l}\text { Upper } \\
\text { limit }\end{array}$ & & \\
\hline Tabibi SJ, et al:2009 & 79.100 & 7.795 & 60.759 & 63.822 & 94.378 & 10.148 & 0.000 \\
\hline Zohoor A and Pilevar Zadeh M, 2003 & 60.000 & 2.569 & 6.600 & 54.965 & 65.035 & 23.355 & 0.000 \\
\hline \multirow[t]{2}{*}{ MaddiNeshat M, et al:2015 } & 159.000 & 5.775 & 33.355 & 147.681 & 170.319 & 27.531 & 0.000 \\
\hline & 99.314 & 32.828 & 1077.706 & 34.971 & 163.656 & 3.025 & 0.002 \\
\hline
\end{tabular}

Mean and $95 \% \mathrm{Cl}$

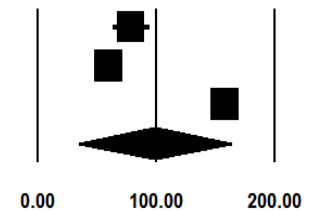

Fig. 7. Frequency distribution of the average waiting time for first specialist consultation in emergency departments Iran

\begin{tabular}{|c|c|c|c|c|c|c|c|}
\hline \multirow{2}{*}{ Study name } & \multirow[b]{2}{*}{ Mean } & \multicolumn{4}{|c|}{ Statistics for each study } & \multirow[b]{2}{*}{ z-Value } & \multirow[b]{2}{*}{ p-Value } \\
\hline & & $\begin{array}{l}\text { Standard } \\
\text { error }\end{array}$ & Variance & $\begin{array}{c}\text { Lower } \\
\text { limit }\end{array}$ & $\begin{array}{c}\text { Upper } \\
\text { limit }\end{array}$ & & \\
\hline Tabibi SJ, et al:2009 & 283.600 & 15.463 & 239.100 & 253.293 & 313.907 & 18.341 & 0.000 \\
\hline Zohoor A and Pilevar Zadeh M, 2003 & 420.000 & 32.697 & 1069.091 & 355.915 & 484.085 & 12.845 & 0.000 \\
\hline Golaghaie $F$, et al:2008 & 244.500 & 15.450 & 238.703 & 214.219 & 274.781 & 15.825 & 0.000 \\
\hline Jabbari A, et al:2011 & 353.100 & 25.302 & 640.213 & 303.508 & 402.692 & 13.955 & 0.000 \\
\hline Amina S, et al:2015 & 210.000 & 15.792 & 249.389 & 179.048 & 240.952 & 13.298 & 0.000 \\
\hline Movahednia S, et al:2013 & 305.000 & 0.775 & 0.601 & 303.481 & 306.519 & 393.495 & 0.000 \\
\hline \multirow{2}{*}{ Khazaei A, et al:2015 } & 133.200 & 2.074 & 4.303 & 129.134 & 137.266 & 64.213 & 0.000 \\
\hline & 276.788 & 45.211 & 2044.015 & 188.176 & 365.400 & 6.122 & 0.000 \\
\hline
\end{tabular}

Mean and $95 \% \mathrm{Cl}$

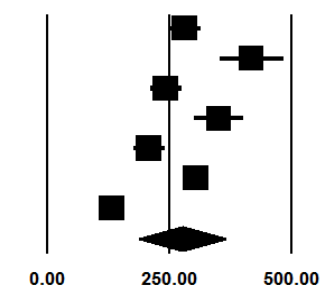

Fig. 8. Frequency distribution of the average total waiting time (entry and exit) in the emergency departments in Iran

hospitals. In which case, we should use a central laboratory of the hospital or other laboratories outside the hospital. In addition, an increased workload on emergency personnel could reduce or delay the handling of emergency patients. Therefore, we recommend hospital emergency departments to be equipped with their own laboratories to perform this service within the department.

The waiting time from referral to radiology and radiology results was estimated to be $34.4 \pm 2.9$ minutes, which compared with international standards particularly standards of Emergency Association of America that recommends it to be 15 minutes (35), is in a more unfavorable situation. One of the reasons that preparing radiology results took a long time was unnecessary demands in the emergency and radiology departments. Since there was not sufficient evidence in this study, investigating the causes of prolongation of time to prepare radiology results seems to be vital in sensitive wards, such as the emergency department. Another possible reason could be the lack of portable X-ray equipment or the radiology department in some hospitals. Thus, providing more facilities in emergency department planning is essential.

The results of this study revealed that overall waiting time of Iranian patients in the emergency department is 4.6 hours (276.7 minutes). A study by the Canadian Institute for Health Information, whose aim was to determine patients' waiting time in the emergency departments of 3 countries (Canada, United States, and Britain), revealed that in Canada, $76 \%$ of the patients, in America 96\%, and in England $72 \%$ have waited less than 4 hours in the emergency services (36). One effective method to reduce waiting time in the emergency department is creating a rapid assessment team, including physicians and nurses; the effectiveness of this method has been proved in different

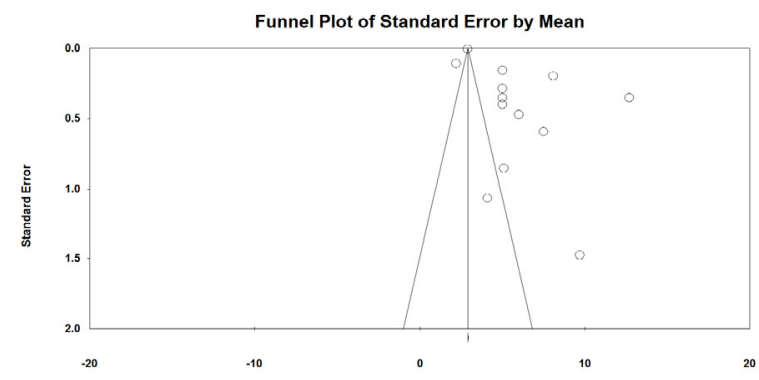

Fig. 9. Funnel plot of standard error by mean 
parts of the world, and its performance by various indicators can improve emergency waiting time (37-43).

Results of the included studies revealed very high standard deviations, which were reported by researchers. The main reason could be the high dispersion of different patients' waiting times at different times. Special cases can also be effective in this case. Quality control diagram is useful in identifying the reasons and resolving this problem. The results also showed a wide difference in waiting times among different cities. The general view seems to be that waiting time is greater in megacities. This could possibly be due to overcrowding and the high volume of referrals to emergency departments in such cities.

The main limitation of this study was related to differences in timing, so the large difference in timing made it impossible to summarize and analyze the results. Therefore, it is recommended that an instruction or national standards be prepared to measure waiting times in the emergency departments of hospitals. In addition, to have an updated and more detailed information, it seems crucial to design and implement a measurement system for waiting times in the emergency department and identify the delays.

\section{Conclusion}

The results of this study indicated that emergency room waiting times in different parts of the country is higher than international and national standards. Considering the importance of providing quality services at the right time and reducing the patients' waiting time, planning and performing interventions in the emergency departments is inevitable. Considering the high rate of heterogeneity in the results and probability of publication bias, we recommend the readers to use the results of this study and pay sufficient attention to this issue.

\section{Conflict of Interests}

The authors declare that they have no competing interests.

\section{References}

1. Bahrami M, Maghsoudi M, Rafiee N, Alfaraj R, Ghasemi N. Evaluating satisfaction of patients referring to emergency ward of Shahid Sadooghi Hospital, Yazd, Iran, in 2013. Int J Health Syst Disaster Manage. 2014;2(3):161-5.

2. Considine J, Shaban RZ, Gerdtz MF, Crellin D. The comparability of emergency department waiting time performance data. Med J Aust. 2012;197(11):618

3., Kristy MG, Bauhoff S, Blanchard JC, Abir M, Smith A, Vesely JV, et al. The Evolving Roles of Emergency Departments. Santa Monica, CA: RAND Corporation, 2013. http://www.rand.org/pubs/research_ briefs/RB9715.html.

4. Schuur JD, Venkatesh AK. The growing role of emergency departments in hospital admissions. N Engl J Med. 2012;367(5):391-3.

5. Morganti KG, Bauhoff S, Blanchard JC, Abir M, Iyer N. The evolving role of emergency departments in the United States: Rand Corporation; 2013.

6. Pitts SR, Pines JM, Handrigan MT, Kellermann AL. National trends in emergency department occupancy, 2001 to 2008: effect of inpatient admissions versus emergency department practice intensity.Ann Emerg Med. 2012;60(6):679-86. e3.

7. Schuur JD, Venkatesh AK. The Growing Role of Emergency Departments in Hospital Admissions. Med J Aust. 2012;367(5):391-3.

8. Affleck A, Parks P, Drummond A, Rowe BH, Ovens HJ. Emergency department overcrowding and access block. Cjem. 2013;15(6):359-84.

9. Braitberg G. Emergency department overcrowding: the solution to any problem is a matter of relativity. Med J Aust. 2012;196:88-9.

10. Cakir OD, Cevik SE, Bulut M, Guneyses O, Aydin SA. Emergency
Department Overcrowding in Turkey: Reasons, Facts and Solutions. JNMA J Nepal Med Assoc. 2014;52(195):878-85.

11. Lin $\mathrm{CH}$, Kao CY, Huang CY. Managing emergency department overcrowding via ambulance diversion: a discrete event simulation model. J Formos Med Assoc. 2015;114(1):64-71.

12. Doshmangir L, Rashidian A, Jafari M, Takian AH, Ravaghi H. Opening the black box: The experiences and lessons from the public hospitals autonomy policy in Iran. Arch Iran Med. 2015; 18(7): 416 - 424.

13. Day A, Oldroyd C. Attempting to reduce the maximum emergency waiting time to 4 hours in England: was the initiative successful?. J Emerg Nurs. 2012;38(4):383-5.

14. Huang EP, Liu SS, Fang CC, Chou HC, Wang CH, Yen ZS, et al. The impact of adding clinical assistants on patient waiting time in a crowded emergency department. Emerg Med J. 2013;30(12):1017-9.

15. Lauks J, Mramor B, Baumgartl K, Maier H, Nickel CH, Bingisser R. Medical Team Evaluation: Effect on Emergency Department Waiting Time and Length of Stay. PloS one. 2016;11(4):e0154372.

16. Iacobucci G. A third of foundation trusts had missed emergency waiting time target at end of 2012. BMJ (Clinical research ed). 2013;346:f1761.

17. Khatiban M, Khazaei A, Karampourian A, Soltanian A, Kimiaie Asadi H, Salimi R, et al. The effects of the Emergency Severity Index triage education via problem-based learning on the triage nurses' performance and the patients' length of stay in the Emergency Department. J Clin Res Paramed Sci. 2014;3(2):63-74.

18. Lau FL, Leung KP. Waiting time in an urban accident and emergency department--a way to improve it. J Accid Emerg Med. 1997;14(5):299301; discussion 2-3.

19. McGillivray D. When should waiting time become a quality of care issue in the paediatric emergency department? Paediatr Child Health. 2003;8(7):415-6.

20. Ebadifard Azar F, Sarabi Asiabar A. Does leadership effectiveness correlates with leadership styles in healthcare executives of Iran University of Medical Sciences. Med J Islam Repub Iran 2015 (27 January). Vol. 29:166.

21. Househ M, Yunus F. Emergency Department Waiting Times (EDWaT): A Patient Flow Management and Quality of Care Rating mHealth Application. Stud Health Technol Inform.. 2014;202:229-32.

22. Jayaprakash N, O'Sullivan R, Bey T, Ahmed SS, Lotfipour S. Crowding and Delivery of Healthcare in Emergency Departments: The European Perspective. West J Emerg Med. 2009;10(4):233-9.

23. Kamali MF, Jain M, Jain AR, Schneider SM. Emergency department waiting room: many requests, many insured and many primary care physician referrals. Int J Emerg Med. 2013;6:35.

24. Golaghaie F, Sarmadian H, Rafiie M, Nejat N. A study on waiting time and length of stay of attendants to emergency department of Valie-Asr Hospital, Arak-Iran. Arak Med Univ J. 2008;11(2):74-83.

25. S Khan K, Kunz R, Kleijnen J, Antes G. Systematic reviews to support evidence-based medicine. Mazurek Melnyk B, editor2011.

26. Poorolajal J, Tajik P, Yazdizadeh B, Sehat M, Salehi A, Rezaei M, et al. Quality Assessment of the Reporting of Cohort Studies before STROBE Statement. Iran J Epidemilogy. 2009;5 (1):17-26.

27. von Elm E, Altman DG, Egger M, Pocock SJ, Gotzsche PC, Vandenbroucke JP. The Strengthening the Reporting of Observational Studies in Epidemiology (STROBE) statement: guidelines for reporting observational studies. Ann Intern Med. 2007;147(8):573-7.

28. von Elm E, Altman DG, Egger M, Pocock SJ, Gotzsche PC, Vandenbroucke JP. The Strengthening the Reporting of Observational Studies in Epidemiology (STROBE) statement: guidelines for reporting observational studies. PLoS Med. 2007;4(10):e296.

29. Li L, Georgiou A, Vecellio E, Eigenstetter A, Toouli G, Wilson R, et al. The Effect of Laboratory Testing on Emergency Department Length of Stay: A Multihospital Longitudinal Study Applying a Crossclassified Random-effect Modeling Approach. Acad Emerg Med. 2015;22(1):38-46.

30. Howanitz P, Steindel S, Cembrowski G, Long T. Emergency department stat test turnaround times. A College of American Pathologists' Q-Probes study for potassium and hemoglobin. Arch Pathol Lab Med. 1992;116:122 - 8 .

31. Holland LL, Smith LL, Blick KE. Reducing Laboratory Turnaround Time Outliers Can Reduce Emergency Department Patient Length of Stay. An Hospital Study. 2005;124(5):672-4.

32. Lee-Lewandrowski E, Corboy D, Lewandrowski K, Sinclair J, McDermot S, Benzer TI. Implementation of a point-of-care satellite laboratory in the emergency department of an academic medical center. 
Impact on test turnaround time and patient emergency department length of stay. Arch Pathol Lab Med. 2003;127(4):456-60.

33. Singer AJ, Viccellio P, Thode HC, Jr., Bock JL, Henry MC. Introduction of a stat laboratory reduces emergency department length of stay. Acad Emerg Med. 2008;15(4):324-8.

34. Lee-Lewandrowski E, Nichols J, Van Cott E, Grisson R, Louissaint $\mathrm{A}$, Benzer T, et al. Implementation of a rapid whole blood D-dimer test in the emergency department of an urban academic medical center: impact on ED length of stay and ancillary test utilization. Am J Clin Pathol. 2009;132(3):326-31.

35. Gold frank L, Henneman P, Ling L, Prescott J, Rosen C, Sama A. Emergency center categorization standards. Acad Emerg Med. 17. 1999;8:638-55.

36. Canadian Institute for Health Information. Understanding Emergency Department waits times [Online]. 2005; Available from: URL: www.cihi.ca/cihiweb/products/Wait times e.pdf/.

37. Aksel G, Bildik F, Demircan A, Keles A, Kilicaslan I, Guler S, et al. Effects of fast-track in a university emergency department through the National Emergency Department Overcrowding Study. J Pak Med Assoc. 2014;64(7):791-7.

38. Bergman B. Fast-track areas in the emergency department: are they ethical? JAAPA. 2012;25(10):57-8.

39. Dinh M, Walker A, Parameswaran A, Enright N. Evaluating the quality of care delivered by an emergency department fast track unit with both nurse practitioners and doctors. AENJ. 2012;15(4):188-94.

40. Dinh MM, Enright N, Walker A, Parameswaran A, Chu M. Determinants of patient satisfaction in an Australian emergency department fast-track setting. EMJ. 2013;30(10):824-7.

41. Hwang CE, Lipman GS, Kane M. Effect of an emergency department fast track on Press-Ganey patient satisfaction scores. West J Emerg Med. 2015;16(1):34-8.

42. Lutze M, Ross M, Chu M, Green T, Dinh M. Patient perceptions of emergency department fast track: a prospective pilot study comparing two models of care. AENJ. 2014;17(3):112-8.

43. Theunissen BH, Lardenoye S, Hannemann PH, Gerritsen K, Brink PR, Poeze M. Fast Track by physician assistants shortens waiting and turnaround times of trauma patients in an emergency department. Eur J Trauma Emerg Surg. 2014;40(1):87-91.

44. Tabibi SJ, Najafi B, Shoaie S. Waiting time in the emergency department in selected hospitals of Iran University of Medical Sciences in 2007. Res Med. 2009;33(2):117-22.

45. Ramazankhani A, Mahfouz pour S, Marzban S, Naghibzadeh- Tahami A, Sarani A. Assessing waiting time patients in emergency ward of Kerman University of Medical Sciences. JHPM. 2016;5(2):20-30.

46. Setoodehzadeh F, Moaref A, Ghanbari Z, Mardani M, Hooshmand Z. Investigation of waiting time for emergency services in an educational in hospital in Shiraz. Sadra Med Sci J. 2014;2(1):83-8.

47. Zohoor A, Pilevar Zadeh M. Study of speed of offering services in emergency department at Kerman Bahonar hospital in 2000. Razi J Med Sci. 2003;10(35):413-9.

48. Jabbari A, Jafarian M, Khorasani E, Ghaffari M, Majlesi M. Emergency Department Waiting Time at Alzahra Hospital. Health Inf Manage. 2011;8(4):500-11.

49. MaddiNeshat M, Roshanaei G, Azimi B, Niknam A. Assessing trauma patients' waiting time and its associated factors referred to an emergency department. Payesh 2015;2:155-65.

50. Masoumpour S, Rahimi S, Kharazmi E, Kavousi Z, Mosalah Nejad $\mathrm{H}$, Abedi Z. Assessing Waiting Time in Emergency Department of Shahid Faghihi Hospital, Shiraz and Presenting Appropriate Strategies Using Quality Function Deployment (QFD) Method, 2011- 2012. Hakim. 2013;16(2):159- 68.

51. Zare Mehrjardi Y, Hoboubati M, Safaee Nik F. Improvement of waiting time for patients referring to emergency room using discrete event simulation. J Shahid Sadoughi Univ Med Sci. 2011; 19(3):30212.

52. Ajami S, Ketabi S, Bagherian MahmoodAbadi H. Reducing Waiting Time in Emergency Department at Ayatollah-Kashani Hospital Using Simulation. J health Admin. 2013;16 (51):84-94.

53. Mahmoodian F, Eqtesadi R, Ghareghan A. Waiting Times in Emergency Department After Using the Emergency Severity Index Triage Tool. Arch Trauma Res. 2014;3(4):e19507.

54. Soleimanpour H, Gholipouri C, Salarilak S, Raoufi P, Vahidi RG, Rouhi AJ, et al. Emergency department patient satisfaction survey in Imam Reza Hospital, Tabriz, Iran. Int J Emerg Med. 2011;4:2.

55. Yamani N, Moosavi S, Alizadeh M, Khorvash F, Ghiasi M. A 360-
Degree Performance Evaluation of Emergency Medicine Ward in Alzahra Hospital. J Pak Med Assoc. 2012;62(3):13-7.

56. Amina S, Barrati A, Sadeghifar J, Sharifi M, Toulideh Z, Gorji HA, et al. Measuring and Analyzing Waiting Time Indicators of Patients' Admitted in Emergency Department: A Case Study. Glob J Health Sci. 2015;8(1):143-9.

57. Movahednia S, Partovishayan Z, Bastanitehrani M. A survey of timing indicators of emergency department at Firoozgar hospital: 2012. J Health Administ. 2013;16(51):95-102.

58. Khazaei A, Khatiban M, Saeidi SZ, Karampourian A, Soltanian AR, Kimiaei Asadi $\mathrm{H}$, et al. Evaluation of factors affecting emergency department length of stay. Sci J Hamdan Univ Med Sci. 2015;23(3):6271. 